Portland State University

PDXScholar

6-6-1978

\title{
A Comparative Study of the Short-Term Auditory Memory Span and Sequence of Language/Learning Disabled Children and Normal Children
}

Kathleen M. McCausland

Portland State University

Follow this and additional works at: https://pdxscholar.library.pdx.edu/open_access_etds

Part of the Psychiatry and Psychology Commons, and the Speech Pathology and Audiology Commons Let us know how access to this document benefits you.

\section{Recommended Citation}

McCausland, Kathleen M., "A Comparative Study of the Short-Term Auditory Memory Span and Sequence of Language/Learning Disabled Children and Normal Children" (1978). Dissertations and Theses. Paper 2855.

https://doi.org/10.15760/etd.2849

This Thesis is brought to you for free and open access. It has been accepted for inclusion in Dissertations and Theses by an authorized administrator of PDXScholar. Please contact us if we can make this document more accessible: pdxscholar@pdx.edu. 
AN ABSTRACT OF THE THESIS OF Kathleen M. McCausland for the Master of Science in speech Communication presented June 6, 1978.

Title: A Comparative Study of the Short-Term Auditory Memory Span and Sequence of Language/Learning Disabled Children and Normal Children.

APPROVED BY MEMBERS OF THE THESIS COMMITTEE:

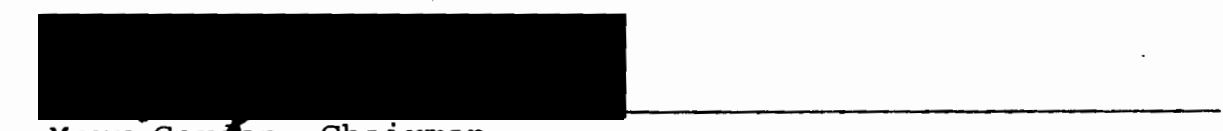
Mary Gorfon, Chairman

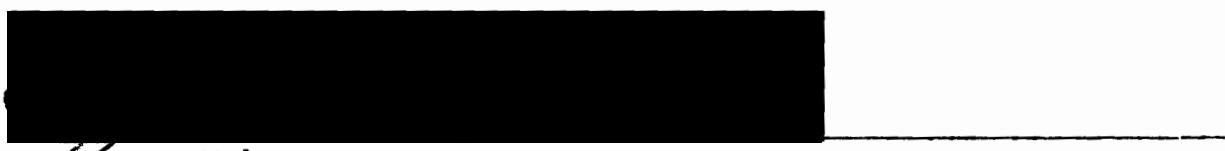

Jan McMahon

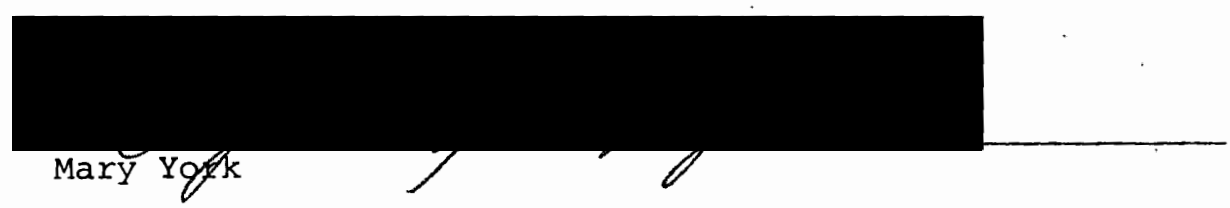

This investigation compared the auditory memory span and sequence of language/learning disabled children with that of normal children to determine if there was a difference between the two groups on short-term auditory memory, ordering of stimulus type difficulty and performance on subtests using various stimulus types. Fifteen LD subjects were matched with fifteen normal subjects for mental age as measured by the Peabody Picture Vocabulary Test. The Auditory Memory Test Battery (AMTB) was administered to each subject. The AMTB consists of five tape recorded subtests of recall for sentences, digits, related words, unrelated words, 
and nonsense words. Each subject responded verbally to the randomly presented subtests. This resulted in ten scores for each subject: a span score and sequence score for each of the five subtests, with a possible twenty-eight points for each subtest for both span and sequence.

The results of this investigation revealed the performance of the LD group to be significantly different from the normal children on all subtests. The normal children performed better on all five subtests for both span and sequence. The ordering of test difficulty from least to most difficult was as follows for both groups: sentences, digits, related words, unrelated words, and nonsense words. It was concluded the LD children were shown to display poorer short-term auditory memory skills than "normal" children. 
A COMPARATIVE STUDY OF THE SHORT-TERM AUDITORY MEMORY SPAN AND SEQUENCE OF LANGUAGE/LEARNING DISABLED CHILDREN AND NORMAL CHILDREN

\title{
by
}

KATHLEEN M. MCCAUSLAND

\author{
A thesis submitted in partial fulfillment of the \\ requirements for the degree of \\ MASTER OF SCIENCE \\ in \\ SPEECH COMMUNICATION : \\ WITH EMPHASIS IN \\ SPEECH PATHOLOGY
}


TO THE OFFICE OF GRADUATE STUDIES AND RESEARCH:

The members of the Committee approve the thesis of Kathleen $M$. McCausland presented June 6, 1978.

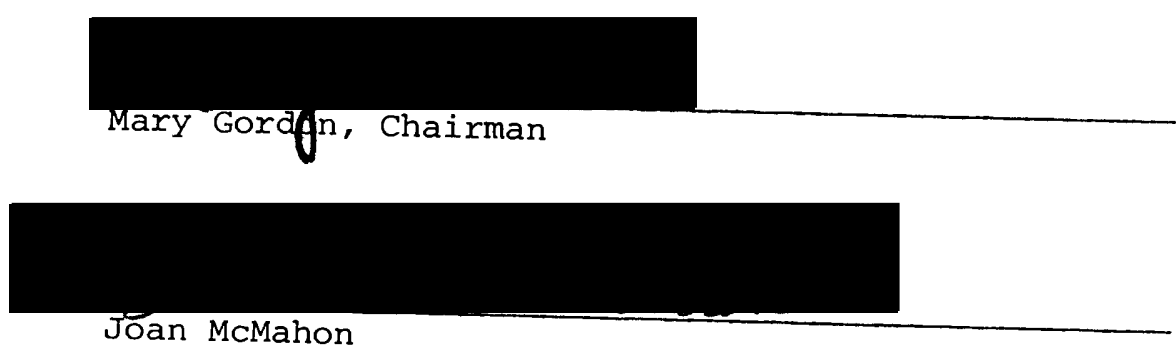

Jŏan McMahon

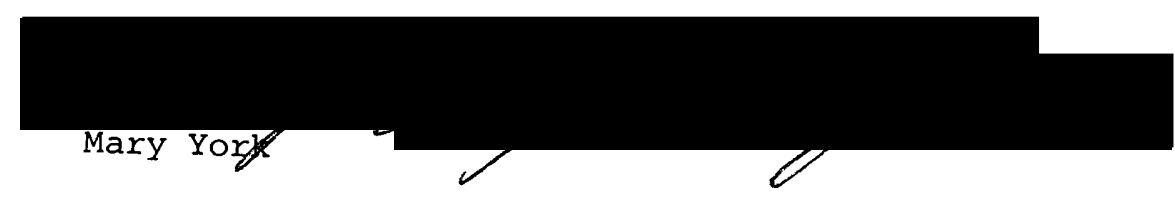

APPROVED :

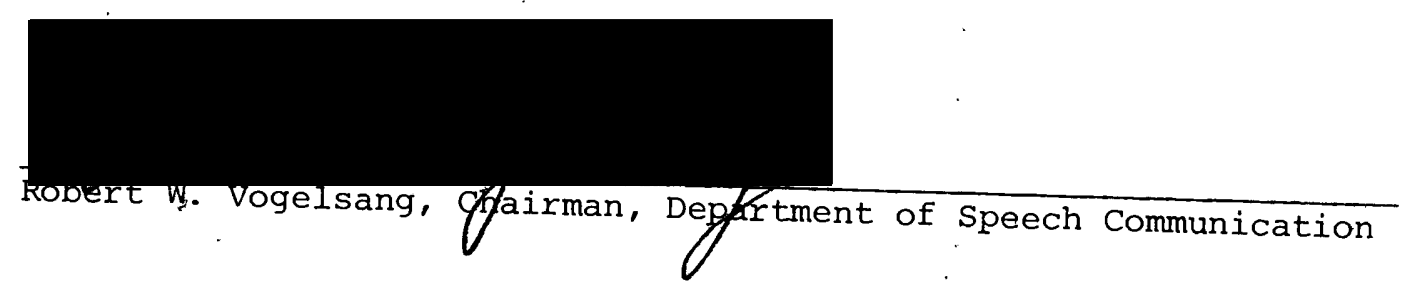

Stanley E. Kauch, Dean of Graduate Studies and Research 


\section{ACKNOWLEDGMENTS}

With the completion of this work comes the time to express appreciation to those individuals that helped make it possible. First, I want to thank Mary Gordon, Committee Chairwoman, for her much needed guidance and support. Her time and assistance were greatly appreciated. Mary is now relieved of finding my frequent notes on her office door. My sincere appreciation goes to Joan McMahon and Mary York, committee members, for their guidance, interest, and valuable input. The kindness and patience along with statistical assistance of Dr. Jack Hegrenes made the data analysis enjoyable and exciting and probably my one and only positive experience with statistics. I want to personally thank my long-time friend, Sharon Swanson, for her typing along with the support and positive attitude through the completion of this work. By the way, the picture of B.G. is on its way. Without the support and co-operation of the Portland Public Schools and the staff of the Language Disorder's Program this project would not have run as smoothly as it did. It is hoped the results will help them in their work. I want to especially thank the classroom teachers and parents at Creston, Lewis, Rose City Park, Sylvan, and Beaumont Schools for their help and willingness to assist me in this study.

Finally, and most importantly, I want to thank my parents, Chuck and Rose McCausland, and brother Jim, for their love and support during my years in school. Their continued support and patience through these years were greatly appreciated. It is to my family I dedicate this work. 
TABLE OF CONTENTS

PAGE

ACKNOWLEDGMENTS iii LIST OF TABLES

CHAPTER

I INTRODUCTION AND STATEMENT OF PURPOSE . . . . . . . . . . . i Statement of Purpose . . . . . . . . . . . . 3 Definition of Terms ................. . . 4

II REVIEW OF THE LITERATURE . . . . . . . . . . . . . 5

Learning Disabilities and Auditory Perception . . . . 5

Measuring Auditory Memory . . . . . . . . . 12

Auditory Memory in Normal Children .. . . . . . 17

Auditory Memory in Learning Disabled Children . . . and Other Groups . . . . . . . . . . . . 18

III METHODS . . . . . . . . . . . . . . . . . . . . 24

Subjects ...................... 24

Instrumentation ................ 25

Test Administration ............... . 27

Scoring Procedures ................ 28

Data Analysis . . . . . . . . . . . . 30

IV RESULTS AND DISCUSSION . . . . . . . . . . . . . . . . 31

Results..................... . 31

Discussion . . . . . . . . . . . . . . 35 
CHAPTER

PAGE

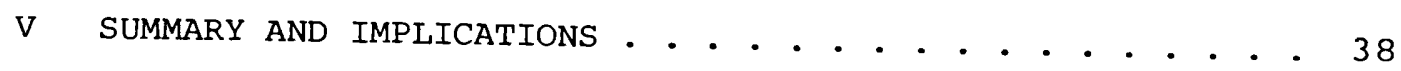

Summary • • • • • • • • • • • • • • • • • • • • 38

Implications • • • • • • • • • • • • • • • • • . 39

Clinical Implications

Research Implications

SELECTED BIBLIOGRAPHY

APPENDICES 


\section{LIST OF TABLES}

TABLE

PAGE

I Subskills of Auditory Perception According to

Researcher . . . . . . ... . . . . . . . . . 9

II Wilcoxon-Matched-Pairs-Signed-Rank-Test Results, Means

and Standard Deviations for Auditory Memory Span and

Sequence Measures . . . . . . . . . . . . 32

III Five Stimulus Types, Ranked in Order of Difficulty

(Least to Most), Mean Subtest Scores for Span and

Sequence . . . . . . . . . . . . . . . 34 
CHAPTER I

INTRODUCTION

In the past, researchers in the field of learning disabilities have tended to neglect the auditory pathway for learning. The research and evaluation methods appear to have focused on visual perception (Lerner, 1971; Wallace and McLoughlin, 1975). The careful observation and analysis given to visual perception has not been applied to auditory perception in spite of its significance during a child's development. School readiness evaluations greatly emphasize visual and motor functioning and often neglect auditory processing and language. This has occurred, despite the importance of listening in a child's early school years (Cicci and zigmond, 1968). It is only recently that more intense investigations into the parameters of auditory perception and its subskills have been carried out (Wallace and McLoughlin, 1975).

Because the majority of research in auditory perception has been performed only recently, definitions vary according to researcher. For the purpose of this study, the term auditory perception is defined as "the central processing of auditory stimuli" (Chalfant and Scheffelin, 1969). It is important to differentiate between the terms auditory perception and auditory acuity. Auditory acuity refers to the ability to "perceive sounds physiologically, whereas auditory perception is a cognitive skill" (Wallace and McLoughlin, 1975). Included within the area of auditory perception are several subskills, one of which is auditory memory. 
A child with auditory perceptual difficulties may have a variety of problems including short and long term memory disturbances (Wallace and Mcloughlin, 1975). The fact that some children who are unsuccessful learners have poor memories was observed long before learning disabilities was a field of study (Lerner, 1971). Memory (auditory or visual), which plays a significant role in almost all types of learning, refers to the ability to store information that has been "sensed, perceived and learned" (Lerner, 1971). Memory also refers to the ability to retrieve that information when needed. Because of the vital role memory plays in learning, a disability in this area may seriously impede other processes of learning. Auditory memory includes the two subskills of span (number of stimuli retained) and memory for sequence (retention of stimuli in serial order).

Various studies have demonstrated that children and adolescents with learning disabilities exhibit evidence of reduction in short term auditory memory span and sequence. Aten and Davis (1968) studied the auditory sequential memory abilities of children identified as minimal cerebral dysfunction (MCD) and normal children. The MCD children performed poorer on short-term perceptual span measures (the number of stimuli retained) and were less accurate on reproduction of sequential information than the normal children. The authors recommended continued assessment of auditory perceptual and oral sequential abilities to help explain hyperactivity and to act as a sensitive indicator to disturbed. cerebral functioning. They also stressed the need for these kinds of tests in differential diagnosis of "functional articulation disorders, dysfluencies and language learning disorders." 
Monsees (1968) studied the ability of expressive language impaired children and normal children to imitate isolated phonemes and six other tasks including sound discrimination, sound sequence blending and sequential phoneme repetition. The study revealed the language impaired children have problems of auditory sequential processing. Implications for reading problems were discussed as predictive from poor performances on sound blending of spoken language and poor temporal sequencing tests.

Chalfant and Schefflin (1969) expressed a need in the field of learning disabilities for more detailed description of specific memory disturbances in children:

...a child may function normally at a concrete, sensory level but as the same child grows older he may experience great difficulty in acquiring, retaining, recalling or recognizing spoken or written symbols.

Research in the area of short term auditory memory span and sequence of language/learning disordered children appears to lack any kind of standardized test battery of different stimulus types with the exception of Burford's (1976) which was administered to normal subjects. The use of digits, words, and sentences appears to be used most frequently, without analysis of the differences among various stimulus types. Scoring also is not usually done for both span and sequence. It appears a test utilizing various stimulus types for analysis may be more sensitive to auditory memory deficiencies in language/learning disabled children.

\section{Statement of Purpose}

The purpose of this investigation was to compare the span and sequence memory of learning disordered with that of normal children using different stimulus types, i.e., digits, nonsense words, related words, 
unrelated words, and sentences. The investigation sought to answer the following questions:

1) Do learning disordered children exhibit a difference in auditory memory span and sequence in comparison to normal children?

2) What is the ordering of difficulty of stimulus types for the learning disordered children? Is it the same as for normal children?

Additionally, two secondary questions were asked:

1) On which stimuli do the learning disordered children score similarly to the normal children?

2) On which stimuli do the normal children score significantly better than the learning disordered children?

\section{Definition of Terms}

Language/Learning Disorders: defined in accordance with the Education of

all Handicapped Children Act of July 1975 which reads as follows:

Those children having a disorder in one or more of the basic psychological processes involved in understanding or using language, spoken or written, including such conditions as perceptual handicaps, brain injury, minimal brain dysfunction, and developmental asphasia, but excluding children who have learning problems which are primarily the result of visual, hearing, or, motor handicaps, or mental retardation; or emotional disturbance, or of environmental, cultural, or economic handicaps.

Additionally, these children may be identified by the following characteristics: 1) average or above intelligence, 2) significant deficit in one or more academic areas, and 3) presence of hyperactivity, difficulty in expressive language and/or short attention span.

Memory Span: the retention of stimuli, but not necessarily in serial order.

Memory for Sequence: the retention of stimuli in serial order.

Stimulus Types: the auditory events the subject is asked to remember and verbally repeat, e.g., related words ("car-bus"), nonsense words ("ort-nar"), and sentences ("find the glove"). 
CHAPTER II

REVIEW OF THE LITERATURE

The review of literature begins with a discussion of children with learning disabilities and auditory perceptual deficits, with an emphasis on auditory memory span and memory for sequence. Secondly, evaluation instruments are described. Finally, research in auditory perception and memory applied to normal and learning disabled children is reviewed.

\section{Learning Disabilities And Auditory Perception}

\section{Learning Disabilities}

A growing concern has developed in recent years for the group of children who, despite normal sensory functioning and intelligence, experience difficulty in learning. Currently, the literature refers to these children by several terms including learning disabled, language disordered, minimal brain dysfunction, developmentally aphasic, and perceptually handicapped. Each of these labels refers to essentially the same set of characteristics as defined by the Education of all Handicapped Children Act of 1975 (see Definitions, p. 4). Children identified as language/learning disordered (LD) are usually diagnostically similar in three characteristics. First, they are of average or above intelligence as measured by an individualized intelligence test. Secondly, they experience a significant deficit (delay of two or more years) in one or more academic areas, commonly reading. Lastly, they may demonstrate one or more of the following characteristics commonly associated 
with learning disabled children: hyperactivity, difficulty in expressive language and short attention span. Children with visual, auditory, emotional, and motor disorders or mental retardation are not considered learning disabled (Gordon, 1977). Eisenson (1972) has viewed learning disabled children and children with developmental aphasia as similar in several behavioral characteristics: perceptual disabilities in one or more, but not all, sensory modalities; auditory disabilities, especially in phonetic discrimination and sequencing; sequencing problems; and "intellectual inefficiency" in relation to actual intellectual potential. As mentioned above, difficulties associated with auditory learning tasks are among the problems LD children may exhibit (Sanders, 1977). Frequently, the learning disabled child's perception of auditory stimuli may be "warped" resulting in his inability to interpret auditory sensations or messages in a normal manner. Perception of auditory stimuli takes place in the brain. The impairment occurs, not in the sensory organ, but in the perception resulting from stimulation to the sensory organ. Thus, the child's ability to perceive and interpret auditory stimuli is somehow impaired (Lerner, 1971; Sanders, 1977).

\section{Auditory Perception}

Researchers reporting in the Iiterature do not reach a concensus as to a single definition of auditory perception. Gearheart (1973) defined auditory perception as "the relatively simple psychological process involving the ability to accurately recognize sensory input or information." Auditory perception was defined by Chalfant and Schefflin (1969) as "the central processing of auditory stimuli." Lerner (1971) defined auditory perception as the "ability to recognize or interpret what is heard." 
still another view was taken by Witkin (1971) when she defined auditory perception as a process "involving focus, attention, tracking, sorting, scanning, comparing, retrieving, and sequencing spoken messages at the moment of utterance."

As a normal child matures, auditory capacities develop and become the foundation for language learning. The child first learns to recognize and identify sound, then make finer and finer discriminations between sounds in the environment. Finally, the child develops skill in auditory memory and reauditorization (internal auditory rehearsal of digits, words and sentences) (zigmond, 1969 and Wiig and Semel, 1976). Eisenson (1972) places great emphasis on auditory abilities for a child producing an oral language code. He states the following capacities need to be acquired for learning oral language: 1) the ability to receive stimuli that occurs in a sequence or order, 2) the ability to hold the sequence in mind, and the sequential impression so its components may be integrated in some pattern, (by either memory or by the application of a rule plus memory), and 3) the ability to scan the pattern from within so it may be compared with other stored patterns or other remembered impressions.

Although visual perception has been given more emphasis in both research and in building children's readiness skills, Lerner (1971) stated educators are beginning to "fully realize the crucial role auditory perception and its disorders plays in learning." Disorders in auditory perception are seen by Eisenson (1972) as "the prime causal factor in most language problems." Johnson and Myklebust (1967) described disturbances of auditory perception as behaviorally of great consequence and 
of extreme importance in the diagnosis and remediation of learning disabilities.

\section{Subskills of Auditory Perception}

In order to understand auditory perception, it is necessary to organize and formulate a category system of auditory perception subskills. Various authors have described what they believe to be the subskills of auditory perception; these vary according to author. Most writers (Flower, 1968; Messing, 1968; Gearheart, 1973; Lerner, 1971; and Gordon, 1977) include auditory discrimination and auditory memory as subskills of auditory perception. In addition, other auditory skills such as auditory sensation, auditory figure-ground, auditory integration and synthesis, and auditory feedback are mentioned. See Table I for a listing of subskills proposed by the various writers.

\section{Auditory Memory}

Memory is one of man's basic concepts and fundamental abilities as every event in life involves a different kind of memory (Cicci and Zigmond, 1968; Chalfant and Scheffelin, 1969). Memory is the ability to retain, recall, and recognize the representations of past experience. It is a highly complex and active process involving attitude, motivation, the individual's learning history, and genetic make-up. It essentially entails all mental functions (Chalfant and Scheffelin, 1969; Sapir and Nitzburg, 1973).

Most research in memory has been directed toward that of shortterm. This is defined as recall in seconds as opposed to long-term memory which is retention for a matter of hours. Auditory memory refers to memory of a stimulus or information related to sound patterns (Cicci 
TABLE I

SUBSKILLS OF AUDITORY PERCEPTION ACCORDING TO RESEARCHER

Researcher

Flower (1968)

\section{Auditory Perception Subskills}

Auditory sensation, auditory attending, auditory discrimination, auditory memory, auditory integrity, auditory-visual integration.

Messing (1968)

Auditory awareness, auditory focus, auditory figure-ground, auditory discrimination, auditory memory, auditory scanning, auditory integration and synthesis, auditory feedback.

Gearheart (1973)

Awareness of sound, localization of sound, auditory discrimination, auditory sequential memory, auditory figure-ground.

Lèner (1971)

Auditory discrimination, auditory memory, auditory sequencing, auditory blending.

Gordon (1977).

Auditory discrimination, auditory memory, auditory sequential memory, auditory figure-ground, sound-symbol association, sound-blending, auditory closure.

and Zigmond, 1968). Two subskills of auditory memory are memory span and memory for sequence (previously defined p. 4).

Auditory memory plays a critical role in the development of language. The process of learning and using language is dependent on memory, as the auditory impression must not only be identified and discriminated, but also retained and available in memory storage (Johnson and Myklebust, 1967). Learning disabled children commonly exhibit deficits in retention, recall and recognition. These memory disturbances may influence various perceptual, linguistic, and cognitive aspects of 
auditory language processing, as well as oral language production (Chalfant and Scheffelin, 1969; Wiig and Semel, 1976). Research reported by Gearheart (1973) and Wiig and Semel (1976) indicate LD children exhibit problems in normal language development, language processing and specific deficits in syntax and morphology as a result of reduced auditory memory span and sequence.

\section{Auditory Memory Span Disabilities}

Johnson and Myklebust (1967) further reported learning disabled children experience difficulties in remembering letter sounds or in the ability to blend sounds together to make words. They may have no difficulty remembering single words, but the amount of information (span) they can remember at one time is impaired. The degree of impairment was not specified. This results in problems following a series of commands or understanding complex verbal instructions (Zigmond, 1969).

\section{Auditory Sequencing Disabilities}

closely related to auditory memory span is auditory sequencing. Sequencing behavior is a necessity for acquisition of language skills and learning in general (Johnson and Myklebust, 1967; Witkin, 1971). Witkin emphasized the importance of sequencing. She contended its importance has been recognized, but still "is receiving little attention experimentally, especially with children who hear normally."

Gearheart (1973) has indicated memory for sequence becomes increasingly important as the child grows older and becomes involved in activities which are more and more complex. An observation commonly made of learning disabled children is their inability to recall and reproduce a sequence of numbers, letters or non-meaningful symbols. Although many 
can correctly repeat meaningful symbol sequences such as sentences, this too is a common sequencing difficulty (Johnson and Myklebust, 1967; McCarthy and McCarthy, 1969). Instructions often cause difficulties for children with auditory sequencing problems as previously described under span difficulties. They become confused and make errors when told, for example, "First close the door, then get your book, bring your chair over here and sit next to Johnny" (Johnson and Myklebust, 1967). Other difficulties resulting from auditory memory sequencing problems may be reflected in the mispronunciation of words and comprehension of words and phrases, e.g., "aminal" for "animal," "muxed-ip" for "mixed-up," "sitterbaby," "wipe shield wiper" and "what there are?" Auditory memory sequencing disorders may also be expressed in the inability to learn in sequence, the days of the week, months of the year, or the alphabet (Johnson and Myklebust, 1967; Cicci and Zigmond, 1968).

\section{Associated Disabilities}

The learning disabled child, as a result of disorders in auditory perception and its subskills memory span and sequence, may experience difficulty in one or more academic areas, i.e., reading, spelling, mathematics or writing (Johnson and Myklebust, 1967; McCarthy and McCarthy, 1969 and Gordon, 1977).

Reading is probably the most researched and discussed academic deficit the learning disabled child experiences (McCarthy and McCarthy, 1969). The relationship between reading and auditory disturbances has frequently been investigated through the study of children with dyslexia. Dyslexia, defined by Myklebust and Johnson (1962) is "a language disorder, an inability to read normally as a result of a dysfunction in the 
brain." It is a type of visual agnosia, which in the past was referred to as word blindness. Those children diagnosed as dyslexic are unable to normally symbolize their experiences verbally (Myklebust and Johnson 1962). Both the children's learning and adjustment may be significantly affected by memory disturbances (Myklebust and Johnson, 1962; Gearheart, 1973). Koppitz (1971) in a five year follow-up study of children with reading disabilities, related problems in auditory memory and sequencing of sounds and symbols to reading disorders. Auditory sequencing problems are seen frequently in dyslexics because auditory sequencing is important in reading. These children lack skills to remember both the order and number of sounds in words (Johnson and Myklebust, 1967).

\section{Measuring Auditory Memory}

Before discussing the individual evaluation instruments available. to test auditory memory span and sequence, consideration must be given to the rationale for assessing these skills. In order for adequate development of language skills to occur, a child must have minimum auditory retention ability. Cicci and zigmond (1968) believe the measurement of memory tests not only memory itself, but a child's understanding of speech and language. Further, deficits in certain types of memory are considered to have diagnostic significance as an indicator of organic and functional disorders (Wiig and Semel, 1976).

The measurement of auditory memory span is frequently a component of the measurement of intelligence. Binet, according to Zigmond (1969), was the first to introduce the auditory memory span test and it has remained an integral part of the evaluation of mental abilities. 
The most widely used measurement of auditory memory span, as reported by Chalfant and Scheffelin (1969), is the number of items, e.g., digits, words, or syllables in a sentence an individual remembers after a single presentation. By increasing the number of stimuli presented, the examiner is able to test the range of elements the subject is able to retain and retrieve. Eight factors, according to chalfant and Scheffelin (1969), have been shown in past research to affect memory retention: number of units previously learned, number of units to be learned, pronounceability, recodability, familiarity, meaningfulness of the unit, duration or retention interval, and activity during retention interval. Also reported by Chalfant and Scheffelin (1969) were sixteen variables effecting memory span. These variables can be applied to both auditory and visual memory. Some of the sixteen identified were: rate of presentation, list length, time of day, fatigue, attitude, syllable length of words, and practice.

The majority of evaluation instruments appropriate for measuring short term auditory memory are subtests of extensive intellectual, psycholinguistic, and learning aptitude tests. The short-term auditory memory of children suspected of having learning disabilities may be assessed by using various stimuli including digit series, repeated forward and backwards; words, both related and unrelated; syllables; sentences; and rhymes (Lerner, 1971; Gearheart, 1973; Wiig and Semel, 1976). Most often testing using these stimuli requires the child to respond verbally to the stimulus presented by the examiner.

The Stanford Binet Intelligence Scale (Terman and Merrill, 1960) has two subtests of auditory short-term memory. The first involves repeating digits forward and reversed with the second assessing memory for 
sentences. The digits are presented at a rate of one per second. One score is given for both span and sequence after a single presentation. The memory for sentences subtest is presented at three age levels: four, eleven, and thirteen. With each level, the number of words in the sentence increases along with grammatical complexity. One score is given for both span and sequence.

The Weschler Intelligence Scale for Children (WISC) (Weschler, 1974) evaluates auditory memory span for digits. It consists of two parts: forward and reversed repetitions. Each subtest contains seven items ranging in length from three to nine digits. The digits reversed subtest ranges in length from two to eight digits. All items are presented at a rate of one per second.

The Auditory Sequential Memory Subtest of the Illinois Test of Psycholinguistic Abilities (Kirk, McCarthy and Kirk, 1968) also evaluates short-term auditory memory utilizing a sequence of digits. The subtest has twenty-eight items of two to eight digits. Scoring provides information on the number of units the child can store in short-term memory and sequencing difficulties. Digits may occur more than once in a series, which may, according to wiig and semel (1976) facilitate recal1. Items are presented at a rate of two per second.

The literature reflects a controversy over the use of digits alone to measure short-term auditory memory. There is a low correlation between digits subtests and measurements of intelligence indicating shortterm auditory memory is not part of intelligence. Further, Cohen (1959) and Cronback (1970) reported the reliability of the WISC digit subtest to be lower than any of its other subtests.. Through factor analysis, Cohen found the subtest not to measure general intelligence, memory, or 
"freedom from distractibility."

In a study related to both digits and rate presentation, Aten and Davis (1968) found the presentation rate of digits, one per second, did not differentiate learning disabled children from matched controls; however, the retention of CVC nouns in the LD children indicated auditory memory span deficits. Due to these results, Wiig and semel (1976) questioned the diagnosis of memory deficits on the basis of digit span tests alone. On the other hand the advantage of utilizing a digit subtest, according to Glasser and zimmerman (1967), may be as a rapid check on verbal memory and attention. The diagnostic value would be in the discrepancy between digits forward and reversed, which could signal "concrete thinking and difficulties performing mental abstraction" (Wiig and Semel, 1976).

Tests of Short-Term Auditory Memory Span and Sequence

The Detroit Tests of Learning Aptitude (Baker and Leland, 1959) contains two subtests for evaluating auditory short-term memory. The first is a span test for unrelated words, consisting of two sets of seven word groups. The sets range in length from two to eight words and are presented at a rate of one per second. The second subtest "related syllables" assesses memory for sentences. The sentences range in length from five words to twenty-two words. The sentences are not controlled for syntacic complexity which, along with linguistic structure and semantic interpretation, are said to facilitate auditory memory for children with learning disabilities (Wiig and semel, 1976).

Wepman and Morancy (1973) developed two individual auditory memory tests, one for span and the other for sequential memory. Both are 
standardized. The Auditory Memory Span Test consists of sixty nouns arranged in five sets. The sets consist of three to six items, with words presented with a one second pause interval between words. The Auditory Sequential Memory Test is an individual test of sequential order recall of digits.

The Goldman-Fristoe-Woodcock Auditory 'Skills Test Battery (1974) contains a set of three auditory memory tests. These measure recognition memory, memory for content (span), and memory for sequence. All three tests utilize memory for words with the auditory stimuli paired with pictures. Verbal test stimuli are presented via pre-recorded tapes. The tests utilize a cassette tape player, pre-recorded tape and easel kit for presentation of the auditory and visual stimuli.

A school screening test which contains two memory subtests, the Meeting Street School Screening Test was devised by Hainsworth and Siqueland in 1969 (in Wiig and Semel, 1976). The test utilizes both words and sentences along with scoring for both span and sequence. The first subtest for memory evaluation, consists of six nonsense words and five unrelated words. The sentence subtest has two sentences, one with six words and the second with eleven. The Meeting Street School Screening Test is considered a screening device for school readiness. Auditory memory is assessed briefly to aid in the identification of children who may not be ready to enter school.

Spencer in (Mills and Kramer, 1977) developed the Memory for Sentence Test. It is an auditory vocal sequencing test of short-term memory, recall and sequential decoding. The individual is given one score for both span and sequence. The format of administration is similar to other memory tests. The sentences are of increasing length, with an 
error of span or sequence resulting in the entire sentence scored as incorrect.

The Auditory Memory Test Battery (AMTB) was developed by Burford (1976) in her thesis on the auditory memory span and sequence of normal children. The AMTB consists of five different stimulus types (fourteen mono-syllable items each) presented via audio-cassette tape. These stimuli consist of unrelated words (those not in same semantic category), nonsense words, digits, sentences, and related words (those in same semantic category). Each subject is scored for span and then sequence, thus giving the child separate span and sequence scores. Stimuli are presented at a rate of two per second.

\section{Auditory Memory in Normal Children}

Abilities in storing auditory stimuli or experiences develop as the child's auditory perception matures and develops (Cicci and Zigmond, 1968). In reviewing the literature on the development of memory for auditory stimuli in children, the work by Terman and Merrill in 1937 is often referred to by investigators. Most frequently Terman and Merrill (in Zigmond, 1969) based their auditory memory span studies on the repetition of digits. They placed the abilities in the following developmental sequence: repeating two digits at two years, three digits at three years, and four digits at four years. Additionally, they reported adults remember seven digits. Cicci and Zigmond (1968) and Zigmond (1969) placed memory for short sentences at four and one-half years. Information regarding specific sentence length was not given by these authors. Overall, auditory memory span was thought to continue to develop well beyond the age of seven (Zigmond, 1969). 
One study concerning the auditory memory span and sequence of normal children was conducted by Burford (1976) who used forty-five normal second, third, and fourth grade students. She investigated the effects of stimulus type on the measurements of short-term auditory memory span and sequence. Her purpose was to determine if the span and sequence measures were the same within each of the five subtests and if span and/or sequence measures varied across all five subtests. Results showed the span and sequence scores for digits differed significantly, with the span test being the easiest. Scores for span and sequence did not differ significantly for related or unrelated words, nonsense words or sentences. A significant difference was found between span and sequence performances according to stimulus. The sequence performance for related and unrelated words was not different. Sentence recall was found, in general to be easier than individual words, and nonsense word recall was the most difficult.

\section{Auditory Memory in Learning Disabled Children and Other Groups}

A 1966 study by Zigmond (reported in 1969) investigated the auditory, visual, and intersensory functionings of twenty-five dyslexic boys and a control group of twenty-five normal boys. The dyslexic children averaged 2.7 years retardation in reading skills. A battery of fifteen auditory and visual tests was administered, including six auditory tests, five of which were for memory and one for auditory discrimination. The five auditory stimuli utilized were nonsense words, digits, words, sentences and rhythmic sequences. The results of the study revealed the dyslexic subjects to be inferior to the controls in both auditory memory and discrimination. In reviewing all fifteen tests, results of eleven 
with at least one auditory component revealed the dyslexics to be inferior to the controls. The researchers concluded deficits in dyslexic children may be specifically related to auditory involvement rather than to visual or intersensory difficulties.

A second analysis was performed by zigmond on the results of the above study. Two scores were derived from each memory test: 1) traditional span score (including sequencing) and 2) gross memory functioning (number of items correct regardless of sequence). It was found that the dyslexic children were inferior in memory with or without sequencing. In other words span and sequence measures differentiated between dyslexics and normal children, but neither span or sequence is a better measure for doing this.

Aten and Davis (1968) investigated the auditory perception, shortterm storage and oral reproduction of sequentially ordered verbal and nonverbal auditory stimuli on twenty-one children with minimal cerebral dysfunction (MCD) and learning disabilities and a comparison group of normal children. The nonverbal tests utilized pure tones and the verbal tests utilized repetition of nonsense syllables, digits, multisyllable words, oral sequencing of syllables, and scrambled sentences. Results indicated the MCD children were significantly deficient compared to controls in performance on all three nonverbal tests and on backward digit span, serial noun, multisyllable word repetition, scrambled sentence arrangement and oral sequential accuracy. Only the nonsense syllables, digits forwards and paragraph recall failed to differentiate impaired functioning in the MCD children. The researchers indicated these results may be attributed to the quality of the recorded samples used in their study. Memory for digits and nonsense syllables was normal for both 
groups; however, the MCD group experienced sequential ordering deficits for multisyllable words, serial nouns, backward digits and scrambled sentences. The researchers provided support for the theory that temporal order difficulties contribute to language and learning disorders and its measurement may aid in differentiating learning disabled children from normal children. It was concluded that children with MCD and LD children performed more poorly than did a control group of normal children as evidenced by their shorter perceptual span, reduced number'of stimuli retained and less accurate sequential reproduction.

In a related study, Monsees (1968) tested the hypothesis that a part of language impaired children's difficulty was related to an inability to process auditory stimuli presented in temporal order. Monsees studied twenty-eight expressive language disordered children and two groups of normal children between the ages of six and twelve. The seven tasks performed by the subjects included repetition and blending of phoneme sequences into words, and repetition and blending of phoneme sequences into non-words. The results revealed the language disordered children showed significantly greater difficulty than the normals on all tasks with the exception of isolated phoneme repetition; these children experienced difficulties in tasks requiring the repetition of phonemes: in sequential order, sequential phoneme blending into words and wordlike wholes and judgement of sequential differences between pairs and nonsense syllables: Monsees concluded a relationship is shown between expressive language disorders and problems of auditory temporal sequencing. The results lend support to those of Aten and Davis (1968) with their group of minimal cerebral dysfunction and learning disabled children. 
Stark (1967) lends support to the observation about the relationship between deficits in temporal sequencing and aphasic language impaired children. He tested thirty aphasic children ranging in age from four to six years with a battery of sequencing subtests. The tests included the auditory-vocal sequencing and visual-motor sequencing subtest of the ITPA, along with the Knox Cube Tapping Test (Stark, 1967). Results indicated the children performed significantly below age level on all the sequencing subtests. Performance on the auditory-vocal-sequencing subtest was more than two years below age level.

Semel and Wiig (1975) reported on their research in auditory language processing deficits associated with learning disabilities in children and adolescents. Among their findings were that LD children exhibited delays in several areas of language including short-term memory deficits for verbal material. The authors described the study of varying the semantic and syntatic constraints on the recall of sentences by LD adolescents. Newcombe and Marshall's experimental sentences (in Wiig and Semel, 1975) were administered to thirty LD and thirty academic achieving adolescents, between the ages of twelve and sixteen years. Results revealed the adolescents with learning disabilities were able to recall significantly fewer sentences verbatim, and made more errors on sentences that violate semantic rules, sentences with correctly or incorrectly sequenced modifier strings, random word strings and complex sentences with embedding. Problems in memory span and sequence appeared to affect the learning disabled children's memory for sentences. From the results, the authors indicated a need for further research into the "channel capacity" or the amount of information that can be handled at any one time and the size of "chunks" which can be held in short-term 
memory store of learning disabled children.

The auditory perception skills of thirty-two learning disabled and thirty-two non-learning disabled culturally different elementary children were compared by McGovern (1976). The children, with a mean chronological age of ten years were administered the Wepman Auditory Discrimination Test and the subtests of the ITPA, auditory sequential memory, auditory closure, and sound-blending. The results revealed a significant difference between the two groups in all areas measured with the LD children performing poorer. A.significant difference was found between the two groups in auditory discrimination, auditory memory, auditory closure, and auditory blending skills. Both groups exhibited a lack of ability in the area of auditory sequential memory. The authors attributed this deficiency to the cultural difference common to both groups. Both groups appeared to demonstrate impaired auditory language ability. The skill of auditory sequential memory appeared to be the least deficient of the four areas measured. The skill of sound-blending, which required the most prerequisite skills, was thought to be the most deficient. The author stressed the importance of establishing skills in auditory language before those in visual language. A child's language development is highly dependent on the auditory modality for learning mostly due to its significant contribution to word meaning. In terms of auditory perceptual skills, McGovern recommended establishing auditory discrimination first, followed by skills of auditory sequential memory, auditory closure, and sound-blending.

Research into auditory memory span and sequence of learning disabled children appears to vary widely in purpose and results. This review dealt with studies relative to the memory span and sequence skills 
of normal children, along with studies investigating these skills in learning disabled, aphasic, dyslexic, and minimal cerebral dysfunction children. The sequencing of auditory stimuli appears to be a factor in language and learning in both learning disordered and normal children. The quality and difficulty of the memory test appears to effect its ability to differentiate normal and learning disabled children. Additionally, it seems variables such as cultural background and types of sentences have an effect on the memory span and sequence abilities of learning disabled children. What appears to be needed is a more complete comparison between $\mathrm{LD}$ and normal children through the use of an auditory memory test that uses a variety of stimulus types and evaluates both span and sequence. Such a comparison should help differentiate the two groups and point to areas of difficulty in the areas of language and learning. 
CHAPTER III

METHODS

\section{Subjects}

The subjects of this investigation were thirty children, consisting of fifteen diagnosed as language/learning disordered and a control group of fifteen normal children. They attended Beaumont, Creston, Lewis, Rose City Park and Sylvan Elementary Schools in Portland, Oregon, and ranged in age from six to nine years. The language/learning disabled (LD) subjects had been diagnosed in the Portland Public Schools as Learning Disordered and were enrolled in a self-contained LD classroom. These children were diagnosed as LD by the results of the WISC-R, various formal and informal language tests, and academic achievements tests. The control group, matched for mental age with the experimental group, was randomly chosen from regular first and second grade classrooms. Permission was obtained from a parent or guardian of each subject to participate in this investigation by a permission request letter signed and returned to this investigator. (See Permission Form, Appendix A).

\section{Criteria for Inclusion in this study}

The criteria for the LD and control group children for inclusion in this investigation were:

1) Received permission from parent or guardian to participate in this investigation. (See Permission Form, Appendix A).

2) Displayed no known physical handicap as determined by classroom teacher. 
3) Passed the articulation screening administered by the school speech pathologist, as determined by consulting the speech pathologist.

4) Passed the audiometric screening, administered by this examiner by responding positively to two of three presentations of $20 \mathrm{~dB}$ for each of the tones $500 \mathrm{~Hz}, 1000 \mathrm{~Hz}, 2000 \mathrm{~Hz}$, and $4000 \mathrm{~Hz}$ bilaterally. Screening was administered at the beginning of the testing session.

Additionally, the control group passed the language screening administered by the school speech pathologist, as determined by consulting the speech pathologist.

Mental age (MA) for each subject was determined by the administration of the'Peabody Picture Vocabulary Test, Form A (Dunn, 1959). Each LD subject was then matched for the same MA \pm 3 months with a control subject.

Subjects were selected with no preference to sex. There were fifteen males and no females for the language/learning disordered group with nine males and six females for the control group.

\section{Instrumentation}

The Auditory Memory Test Battery (AMTB) (Burford, 1976) (see Appendix B) consists of the following subtests:

1) Unrelated Word Sequencing

2) Digit sequencing

3) Sentence Sequencing

4) Nonsense Word Sequencing

5) Related Word Sequencing

Each subtest of the AMTB was comprised of the following: 1) two sample items, each two mono-syllables in length, at the beginning of each subtest and'2) fourteen test items ranging in length from two to 
eight monosyllables. Sexial word items were presented at a rate of two per second with falling vocal inflection at the end of each sequence. Sentence items were presented at a rate of two words per second, using normal inflection. A ten second pause followed each item as time for the subject to respond. Each item had two trials and two response periods. All subtests were prerecorded on cassette tape using the voice of Burford. This study utilized the AMTB because of the five stimulus types. The other tests measuring auditory memory do not contain this number of stimulus types and most do not score separately for span and sequence.

The Peabody Picture Vocabulary Test (Form A), (Dunn, 1959) was utilized to determine mental age by assessing receptive vocabulary age. The test measures comprehension of nouns, progressive tense verbs and adjectives. It is composed of three demonstration plates and one hundred and fifty test plates. Each plate consists of four black and white line drawings, three foils and one target item. The stimulus words are presented in order of increasing difficulty. Stimulus words are read aloud by the examiner, and the child points to the picture best representing the meaning of the word. The test has two forms, A and B, with normative data available for both. Test scores may be converted into mental age, IQ, standard score, and percentile equivalent.

The reliability of the PPVT is .97 . Correlations are reported to be .71 with the Stanford-Binet and .61 with the WISC Full-Scale IQ (Wiig and Semel, 1976).

\section{Recording Instruments}

The five subtests of the AMTB were duplicated from reel tape onto 
five individual cassette tapes. This was carried out using Maxcell C-30 cassette tapes. Each subtest was then given a number (1-5) for later use in randomizing the ordering of administration of the subtests.

The audiometric screening of the subjects was completed utilizing a Beltone portable audiometer model \#10c.

The cassette tape recorder utilized for AMTB administration to all subjects was a Pioneer Centrex, model \# KD-12.

\section{Test Administration}

The examiner walked with each child from his/her classroom to the testing room, while engaging the subject in casual conversation to gain rapport. The hearing screening, PPVT and $\underline{\text { AMTB }}$ were administered in a relatively quiet room in the student's school. If noise conditions outside the room increased, the AMTB tape was turned off until the noise level returned to normal. During the testing period, each subject sat at a small table across from the examiner. The cassette tape recorder, subtest tapes and response form were placed to the right of the examiner. Response forms and lists of subjects were placed out of the subject's line of vision.

Before beginning the test administration, the examiner noted the subject's name and gave the subject a subtest randomizing number (subtest randomizing list, Appendix C) on a response form (See Response Form, Appendix B). The first subject received the first randomizing order (54213), the second subject the second ordering (42531) etcetera. For example, subject \#l was administered the subtests in the following order: sentences (\#5), unrelated words (\#4), nonsense words (\#2), digits (\#1), and related words (\#3); whereas, subject \#2 received the tests in the 
following order (42531).

The examinex gave the following verbal instructions to each subject:

I am going to play five tapes for you. On each tape there will be a lady saying some words. Please listen very carefully to what the lady says. Whenever she stops you say the same thing she just did. The lady will say the words two times. She will say them, then you say them; she will say the words again, then you say them again. Some of the things she will say will be harder to remember than others, and some won't make sense. Just listen carefully and do the best you can to say exactly what she says.

The examiner played the two trial items on the first tape. If the subject failed to respond to at least the second trial of the first sample item, the tape was stopped, the subject re-instructed and the second sample item played. The tape was not turned off again unless the subject failed two consecutive test items on both trials, at which time the subtest was discontinued. After each subtest was administered, the examiner gave positive reinforcement such as "you're going fine" and the instructions, "listen carefully; the next tape will be different from this last one." The above administration procedures were followed for all five subtests. Prior to the administration of the nonsense word subtest the following instructions were given: "These won't make sense." Administration of the hearing screening, PPVT, and AMTB was completed in one session and in an average of 30 minutes.

\section{Scoring Procedures}

Responses were recorded by the examiner during the administration of each subtest. The following procedure was utilized to record all responses:

1) A totally correct response on either trial of an item was recorded by placing a check $(\checkmark)$ beside the item on the response form 
(See Appendix B).

2) Criteria for correctness were:

a) All words in an item had to be named.

b) All words within an item had to be in correct serial order.

c) All words in responses to digits, related words, and sentences items had to match the stimulus words exactly.

d) All words in responses to unrelated word and nonsense word items could deviate by one distinctive feature for one consonant per word (Drexler, 1974). An example of a deviation of one distinctive feature is the response "card" to stimulus "cart."

3) An incorrect response on either trial of an item was recorded by noting the error directly below the stimulus on the response form. Digit responses were noted as digits, word responses as words, and nonsense word responses as phonetic symbols using the International Phonetic Alphabet. All unintelligible responses were noted as such on the response form.

4) If the response to the first trial on any item was correct, the second trial on that item was administered but not scored.

After administration of the AMTB, items were scored for both span (all words in an item recalled) and sequence (all words' in correct serial order). The scoring procedure was as follows:

1) Responses completely correct on the first trial earned two points each for span and sequence.

2) Responses completely correct on the second trial earned one point each for span and sequence.

3) Responses including all words in an item, but not in correct serial order, on the first trial earned two points for span and none for sequence. 
4) Responses including all words in an item, but not in correct serial order, on the second trial earned one point for span and none for sequence.

For any responses to two trials of an item, the subject was credited with the greater number of points earned for span. If, for example, the subject recalled all of the words in an item on the first trial, but erred in the serial order, then went on to respond correctly on the second trial, the subject earned two points for span and one point for sequence on that item.

A total span score was derived for each of the five subtests by summing the span scores within the subtest. The same procedure was used to derive a total sequence score. Each subject then obtained 10 total scores: a span score and a sequence score for each of the five subtests, with a possible twenty-eight points for each subtest for span and sequence.

\section{Data Analysis}

Data analysis was completed using the Wilcoxon-Matched-Pairs-SignedRanks Test (Siegel, 1956) to determine the significant differences between the LD and normal children for memory span and sequence. A desciptive analysis using the mean subtest scores for both span and sequence was used to determine the ordering of difficulty. 
CHAPTER IV

RESULTS AND DISCUSSION

\section{Results}

This investigation compared the auditory memory span and sequence of language/learning disabled children with that of normal children using five stimulus types. This investigation sought to answer the four questions posed at the onset of this study. Questions and results of investigation follow.

The first question posed was: Do LD children exhibit a difference in auditory memory span and sequence in comparison to normal children? The Wilcoxon-Matched-Pairs-Signed-Rank Test for related samples was used to determine the difference between the two groups. Table II displays the results. For the span scores a statistically significant difference between the two groups was found for related words (.005), unrelated words (.005), sentences (.005), digits (.025), and nonsense words (.05). For the sequence scores a statistically significant difference between the two groups was found for sentences (.005), related words (.005), unrelated words (.005), digits (.005), and nonsense words (.05). These results reveal a difference in both the memory span and sequence between the two groups, on all five stimulus types with the normal children scoring significantly better on all stimulus types.

The second primary question posed in this investigation was: What is the ordering of difficulty of stimulus types for the LD children? 
TABLE II

WILCOXON-MATCHED-PAIRS-SIGNED-RANK TEST RESULTS

MEANS AND STANDARD DEVIATIONS FOR AUDITORY

MEMORY SPAN AND SEQUENCE MEASURES

\begin{tabular}{|c|c|c|c|c|c|}
\hline SPAN MEASURES & GROUP & $\overline{\mathrm{x}}$ & $\begin{array}{l}\text { STANDARD } \\
\text { DEVIATION }\end{array}$ & $\mathrm{N}$ & T-SCORE \\
\hline Sentences & $\begin{array}{l}\text { Exp. } \\
\text { Control }\end{array}$ & $\begin{array}{l}24.4 \\
27.53\end{array}$ & $\begin{array}{r}3.62 \\
.92\end{array}$ & 11 & 1. $5 * \star \star$ \\
\hline Digits & $\begin{array}{l}\text { Exp. } \\
\text { Control }\end{array}$ & $\begin{array}{l}13.07 \\
16.2\end{array}$ & $\begin{array}{l}2.34 \\
2.98\end{array}$ & 13 & $11 * *$ \\
\hline $\begin{array}{l}\text { Related } \\
\text { Words }\end{array}$ & $\begin{array}{l}\text { Exp. } \\
\text { Control }\end{array}$ & $\begin{array}{l}10.00 \\
12.80\end{array}$ & $\begin{array}{l}1.69 \\
2.65\end{array}$ & 13 & $3 * \star *$ \\
\hline $\begin{array}{l}\text { Unrelated } \\
\text { Words }\end{array}$ & $\begin{array}{l}\text { Exp. } \\
\text { Control }\end{array}$ & $\begin{array}{r}9.14 \\
12.07\end{array}$ & $\begin{array}{l}1.75 \\
2.49\end{array}$ & 15 & $1.5 * * *$ \\
\hline $\begin{array}{l}\text { Nonsense } \\
\text { Words }\end{array}$ & $\begin{array}{l}\text { Exp. } \\
\text { Control }\end{array}$ & $\begin{array}{l}4.20 \\
5.33\end{array}$ & $\begin{array}{l}1.82 \\
2.23\end{array}$ & 10 & . $11.5^{*}$ \\
\hline
\end{tabular}

SEQUENCE MEASURES

\begin{tabular}{|c|c|c|c|c|c|}
\hline \multirow[t]{2}{*}{ Sentences } & Exp. & 24.4 & 3.62 & \multirow[t]{3}{*}{11} & \multirow{2}{*}{$1.5 * \star \star$} \\
\hline & Control & 27.53 & .92 & & \\
\hline & . & & & & . \\
\hline Digits & Exp. & 12.2 & 1.78 & 9 & $9 * * *$ \\
\hline , & Control & 15.6 & 3.07 & & : \\
\hline Related & Exp. & 9.80 & 1.86 & 12 & $2 \cdot 5 * \star \star$ \\
\hline Words & Control & 12.66 & 2.55 & & \\
\hline Unrelated & Exp. & 9.10 & 1.52 & 15 & $1.5 * \star \star$ \\
\hline Words & Control & 11.73 & 2.12 & & \\
\hline Nonsense & Exp. & 4.20 & 1.82 & 10 & $11.5 *$ \\
\hline Words & Control & 5.33 & 2.23 & & \\
\hline
\end{tabular}

*significant at .05 level

** significant at .025 level

***significant at .005 level 
Is it the same as for normal children? A descriptive analysis using the mean subtest scores for both span and sequence. was used to determine the ordering of difficulty. Table III displays the results. The ordering of subtest difficulty for the LD group from least difficult to most difficult was the same for both span and sequence subtests. The following is the order of subtest difficulty from least to most difficult: sentences, digits, related words, unrelated words and nonsense words. The ordering of difficulty was the same for LD children as for the normal children in both span and sequence subtests. Therefore, both groups displayed the same ordering of difficulty of the five stimulus types:

The first secondary question posed was: On which stimuli do the language/learning diabled children score similarly to the normal children? The Wilcoxon-Matched-Pairs-Signed-Rank Test was used to determine similarities and differences between the individual subtests. Table II displays the results. The results reveal a significant difference between the LD and normals on all the subtests. The normal children performed better on all the subtests. With these results, it may be said the LD children did not score similarly to the normal children on any of the five subtests.

The final secondary question in this investigation was: On which stimuli do the normal children score significantly better than the LD children? Table II displays these results. It was found that the normal children scored significantly better on the sentences, digits, related words, unrelated words and nonsense words subtests for both span and sequence. The overall mean subtest scores showed the normal children to score better than the LD children in both span and sequence memorý. 
TABLE III

FIVE STIMULUS TYPES, RANKED IN ORDER OF DIFFICULTY

(LEAST TO MOST), MEAN SUBTEST SCORES

FOR SPAN AND SEQUENCE

LANGUAGE DISORDERED SUBJECTS

\begin{tabular}{llll}
\hline Span Subtests & $\overline{\mathrm{x}}$ & Sequence Subtests & $\overline{\mathrm{x}}$ \\
\hline Sentences & 24.4 & Sentences & 24.4 \\
Digits & 13.07 & Digits & 12.2 \\
Related Words & 10.00 & Related Words & 9.80 \\
Unrelated Words & 9.14 & Unrelated Words & 9.10 \\
Nonsense Words & 4.20 & Nonsense Words & 4.20 \\
\end{tabular}

NORMAL SUBJECTS

\begin{tabular}{llll}
\hline Span Subtests & $\overline{\mathrm{x}}$ & Sequence Subtests & $\overline{\mathrm{x}}$ \\
\hline Sentences & 27.53 & Sentences & 27.53 \\
Digits & 16.2 & Digits & 15.6 \\
Related Words & 12.80 & Related Words & 12.66 \\
Unrelated Words & 12.07 & Unrelated Words & 11.73 \\
Nonsense Words & 5.33 & Nonsense Words & 5.33 \\
\end{tabular}




\section{Discussion}

The results of this investigation appear to lend support to the literature which indicates that LD children exhibit a difference in auditory memory span and memory for sequence in comparison to normal children. This was the case for various stimulus types tested.

Results of the first question support the findings of zigmond (1969) that dyslexic children are inferior to control subjects in auditory memory. Zigmond's second hypothesis is also supported in finding the LD children are inferior in memory, with and without sequencing. This investigation found the LD children's memory skills to be inferior to the control group in both areas of span and sequence, and on all five stimulus types: Results are also in agreement that neither span nor sequence appears to be significantly better in differentiating between LD and normal children.

This investigation also supports the results of Monsee's 1968 study of language impaired and normal children. Her results indicated LD children showèd significantly greater difficulty in processing auditory stimuli than normal children. This study revealed the LD children to score significantly lower than normal children on all five stimulus types, thus demonstrating greater difficulty with auditory memory stimuli.

Wiig and semel (1975) found LD children recalled significantly fewer sentences and experienced sequencing difficulties in comparison to normal children. The results of this investigation show LD children performing poorer on all stimulus types including sentences, for both span and sequence. 
Burford (1976) utilized the AMTB to study the effect of stimulus type on the auditory memory span and sequence of normal children. Her results are supported by this investigation in regard to ordering of difficulty of stimulus types. Burford reported sentence recall to be generally easier than individual words, and nonsense word recall to be the most difficult. This investigation, as answered by question two, found the ordering of stimulus type difficulty to be the same. Sentences were the least difficult for span and sequence in both groups, followed by digits, related words, unrelated words, with nonsense words being the most difficult for both groups. This ordering of difficulty appears to support the factors affecting memory retention reported by Chalfant and Scheffelin (1965), which include pronounceability, familiarity and meaningfulness of the unit. The sentence stimuli have several factors which contribute to their being the least difficult. These include the above mentioned and also the syntactical structure and semantic relationships of the sentence. The digit stimuli come from a limited selection of numbers, i.e., one thrbuah ten, and one-syllable numbers. Thus, the child has less of a selelction to choose from when recalling these stimuli. This may be said for related words, also, as only a limited number of words can be paired as rellated. For the two most difficult stimuli, unrelated words, and nonselse words, the factors of selection limitation and semantic relations weje not present to aid in recall. Factors adding to the difficulty for ronsense words included the lack of familiarity, pronounceability and meaningfulness of the unit.

The results of questions three and four appear to support the results of Aten and Davis (1968) in their study df children with Minimal 
Cerebral Dysfunction (MCD) and normal children. The researchers used various stimulus types to test the auditory perception, short-term memory and oral reproduction of sequentially ordered verbal stimuli. Unlike the results of this study, Aten and Davis found the MCD children performed similarly to the normal children on nonsense words and digit stimuli, however, the MCD children experienced greater difficulties in sequential ordering of multi-syllable words, serial nouns, backward digits, and scrambled sentences. The researchers concluded the MCD children performed more poorly than did the control group of normal children as evidenced by their shorter perceptual span, reduced number of stimuli retained and less accurate sequential reproduction. Although this investigation used different stimuli than Aten and Davis, the results were quite similar with the exception of digits and nonsense words stimuli. From the results of this investigation it may be concluded the ID children performed poorer on all the stimulus types than the control group of normal children. The same conclusions of Aten and Davis may be drawn regarding results of poorer performance by the LD children. These children, as in the Aten and Davis study, exhibited shorter auditory memory span, a reduced number of stimuli retained and less accurate sequential reproduction on the five stimulus types in comparison to the normal children.

Prior to obtaining the results, it was thought LD children may perform similarly to "normal" children on some stimuli, but not on others. This was not the case. It thus seems LD children tend to have a generalized deficit, rather than a specific one, in short-term auditory memory. This certainly has implications for evaluation and management programs for short-term auditory memory in LD children. 
CHAPTER V

SUMMARY AND IMPLICATIONS

\section{Summary}

This investigation compared the auditory memory span and sequence of language/learning disabled children with that of normal children to determine if there was a difference between the two groups on short-term auditory memory, ordering of stimulus type difficulty and performance on subtests using various stimulus types. Fifteen LD subjects were matched with fifteen normal subjects for mental age as measured by the Peabody Picture Vocabulary Test. The Auditory Memory Test Battery (AMTB) was administered to each subject. The AMTB consists of five tape recorded subtests of recall for sentences, digits, related words, unrelated words, and nonsense words. Each subject responded verbally to the randomly presented subtests. This resulted in ten scores for each subject: a span score and sequence score for each of the five subtests, with a possible twenty-eight points for each subtest for both span and sequence.

The results of this investigation revealed the performance of the LD group to be significantly different from the normal children on all subtests. The normal children performed better on all five subtests for both span and sequence. The ordering of test difficulty from least to most difficult was as follows for both groups: sentences, digits, related words, unrelated words, and nonsense words. It was concluded the 
LD children were shown to display poorer short-term auditory memory skills than "normal" children.

\section{Implications}

\section{Clinical Implications}

The results of this investigation involving the auditory memory span and sequence of LD children shows these children to perform poorer on all five stimulus types tested in comparison to normal children. Thus, any combination of the subtests could be used when diagnosing for language/learning disabilities. Possibly a combination of two or three subtests of varying difficulty, such as sentences, unrelated words, and nonsense words, would aid in the evaluation. Both span and sequence should be measured to not only differentiate between groups, but also to indicate a child's individual strengths and weaknesses.

The use of digits in other memory tests is supported by the results of this investigation. This may be said because digit scores differentiated between the LD and normal children. As digits were the second least difficult subtest for the two groups, it would be advisable when diagnosing to use digit stimuli in combination with other stimuli found to be more difficult such as unrelated words and/or nonsense words. These subtests appear to measure more "pure" memory skills than digits, as they rely less on factors such as semantic relationships and less limitation in choice of stimuli.

McGovern (1976) discussed a skill heirarchy involving auditory abilities for both LD and normal children. The author stated the child should first learn to discriminate auditory stimuli, then to perform auditory sequential memory tasks, and lastly to do auditory closure and 
sound-blending tasks. The results of this investigation describe a heirarchy of difficulty for the stimulus types which can be used when practicing memory skills. With the ID child, it seems logical to begin with the easiest stimuli (sentences) in order to provide early success and aid in motivation. The other stimuli could follow in sequence of difficulty as the child's skills develop.

Upon visual inspection of the scores for span and sequence, very strong similarities were found between the two types of scores. The mean differences were never more than one point apart. These results indicate the teaching of overall memory skills would be inclusive of sequence.

\section{Research Implications}

Since there was little difference between span and sequence scores, the question arose concerning the role the instructions played in the actual resultant scores. It would be interesting to examine span versus sequence performance using different instructions for each, e.g., for span: "remember and repeat as much as you can," and sequence: "remember and repeat exactly what is said." These instructions could possibly change the overall results. Further research is needed.

With this investigation, the AMTB has been shown to be an aid in differentiating between normal and language/learning disabled children. Further investigation using this instrument on different special populations would benefit our overall understanding of memory skills and specifically the teaching of memory skills. Research using the AMTB with aphasic persons would contribute to understanding the memory difficulties for semantic categories that these individuals experience. 
Finally, the standardization of the AMTB on a normal population of children would greatly add to its use as a diagnostic instrument and as a tool to aid in the management of auditory memory disorders. 
SELECTED BIBLIOGRAPHY

Aten, J.L., and Davis, J., Disturbances in the perception of auditory sequence in children with minimal cerebral dysfunction. Journal of Speech and Hearing Research, 11, 236-245 (1968).

Baker, H., and Leland, B., Detroit Tests of Learning Aptitude. Indianapolis: Bobbs-Merrill (1959).

Burford, S.L., "Auditory Short-term Memory Span and Sequence for Five Different Stimulus Types," Masters Thesis, Portland State University (1976).

Chalfant, J.C., and Scheffelin, M.A., Central Processing Dysfunctions in Children: A Review of Research. Bethesda, Md.: U.S. Department of Health, Education and Welfare (1969).

Cicci, R., and zigmond, N.K., Auditory Learning. San Rafael, Cal.: Dimensions Publ. Co. (1968).

Cohen, J., The factorial structure of the WISC at ages $7 \frac{1}{2}, 10 \frac{1}{2}$, and $13 \frac{1}{2}$. Journal of Consulting Psychology, 23, 285-299, (1959), cited by E.H. Wiig and E.M. Semel, Language Disabilities in Children and Adolescents. Columbus: Charles E. Merrill (1976).

Cronbach, L.J., Essentials of psychological testing. New York: Harper and Row (1970), cited by E.H. Wiig and E.M. Semel, Language Disabilities in Children and Adolescents. Columbus: Charles E. Merrill (1976).

Drexler, H.G., A simplified application of distinctive feature analysis to articulation therapy. Journal of Oregon speech and Hearing Association, 15, 2-5 (1976).

Dunn, L.M., Peabody Picture Vocabulary Test. American Guidance Service Inc., Circle Pines, Minnesota (1959).

Eisenson, J., Aphasia in Children. New York: Harper and Row (1972).

Flower, R.M., The evaluation of auditory abilities in the appraisal of children with reading problems. In H.K. Smith, Perception and Reading. Newark, Del.: International Reading Association, (1968), cited by J.W. Lerner, Chilaren with Learning Disabilities. Boston: Houghton Mifflin Co. (1971).

Gearheart, B.R., Learning Disabilities: Educational Strategies. St. Louis: C.V. Mosby Co. (1973). 
Glasser, A.J., and Zimmerman, I.L., Clinical Interpretation of the Weschler Intelligence Scale for Children. New York: Grune and Stratton (1967), cited by E.H. Wiig and E.M. Semel, Language Disabilities in Children and Adolescents. Columbus: Charles E. Merrill (1976).

Goldman, R., Fristoe, M., and Woodcock, R.W., Technical Manual for Goldman-Fristoe-Woodcock Auditory Skills Battery. Circle Pines, Minnesota: American Guidance Service (1974).

Gordon, M., "Subskills of Auditory Perception," lecture presented at Portland State University, Portland, Oregon, Winter (1977).

Johnson, D.J., and Myklebust, H.R., Educational Principles and Practices. New York: Grune and Stratton (1967).

Kirk, S., McCarthy, J., and Kirk, W., Illinois Test of Psycholinguistic Abilities. Champaign, Illinois: University of Illinois Press (1968).

Koppitz, E.M., Children with Learning Disabilities, A 5 Year Follow-up Study. New York: Grune and Stratton (1971).

Lerner, J.W., Children with Learning Disabilities: Theories, Diagnosis and Teaching Strategies. Boston: Houghton Mifflin Co. (1971).

Messing, E.S., Auditory perception: What is it? In J. Auna (Ed.) Successful programming: Many points of view. Fifth Annual Conference Proceedings, Association of Children with Learning Disabilities. San Rafael, Calif.: Academic Therapy Publ., 439-452, (1968), cited by J.W. Lerner, Children with Learning Disabilities. Boston: Houghton Mifflin Co. (1971).

McCarthy, J., and McCarthy, J., Learning Disabilities. Boston: Allyn and Bacon (1969).

McGovern, J.E., "Auditory Perception in Learning Disabled and Nonlearning Disabled Culturally Different Pupils," paper presented at the International Scientific Conference of International Federation of Learning Disabilities, Montreal, Canada, August 9-13 (1976).

Mills, N.B., and Kramer, J.A., A quick screening device for the busy public school clinician. Journal of the Oregon Speech and Hearing Association, 16, 7-10 (1977).

Monsees, E.K., Temporal sequence and expressive language disorders. Exceptional Children, 35, 141-147 (1968).

Myklebust, H.R., and Johnson, D.J., Dyslexia in children. Exceptional Children, 29, 14-17 (1962).

Sanders, D.A., Auditory Perception of Speech, An Introduction to Principles and Problems. Englewood Cliffs: Prentice Hall (1977). 
Sapir, S.G., and Nitzburg, A.C., Children with Learning Problems: Readings in a Developmental-Interaction Approach. New York: Brunner/ Mazel Publ. (1973).

Semel, E.M., and Wiig, E.H., "Language Processing Deficits in Learning Disabled Children and Adolescents," paper presented at the International Scientific Conference of International Federation of Learning Disabilities, Brussels, Belgium, January 3-7 (1975).

Siegel, S., Nonparametric Statistics for the Behavioral Sciences. New York: McGraw-Hill (1956).

Stark, J., A comparison of the performance of aphasic children on three sequencing tests. Journal of Communication Disorders, $1,31-34$ (1967).

Terman, L.M., and Merrill, M., Stanford-Binet Intelligence Scale. Boston: Houghton Mifflin Co. (1960).

Wallace, G., and McLoughlin, J.A., Learning Disabilities: Concepts and Characteristics. Columbus: Charles and Merrill (1975).

Wepman, J.M., and Morency, A., A Manual for Administration, Scoring and Interpretation of the Auditory Memory Span Test. University of Chicago (1973).

Weschler, D., Manual for the Weschler Intelligence Scale for ChildrenRevised. New York: Psychological Corporation (1974).

Wiig, E.H., and Semel, E.M., Language Disabilities in Children and Adolescents. Columbus: Charles E. Merrill (1976).

Witkin, B.R., Auditory perception-implications for language development, Language, Speech and Hearing Services in Schools, 2, 31-51 (1971).

Zigmond, N.K., "Auditory Processes in Children with Learning Disabilities," in L. Tarnopol (Ed.), Learning Disabilities. Springfield, Ill.: Charles C. Thomas (1969). 
APPENDICES 


\section{APPENDIX A}

\section{PARENT PERMISSION FORM}

Dear Parent or Guardian:

I am a graduate student at Portland State University, conducting a research project in Speech and Hearing Sciences. I am attempting to find out more about the memory skills of school-age children. I have received permission from the Portland Public Schools to gather my data in District Number One. The results will be available to teachers and should help them plan and organize school programs.

This study can be accomplished by administering the following evaluation instruments: hearing screening, Peabody Picture Vocabulary Text and the Auditory Memory Test Battery. For the Peabody Picture Vocabulary Test the subjects will point to pictures named by the examiner. The Auditory Memory Test Battery will require listening to recorded sequences of words and repeating them back.

The evaluation will be done by myself, Kathy McCausland, during a 3 week period. The procedure will take 45 minutes of your child's time. In no way will your child's name be used in reporting the results of this study.

I am requesting your permission for your child to participate in the project outlined above. Please sign below indicating your approval and return with your child to school tomorrow.

Thank you for your help.

Sincerely,

Kathy McCausland, Graduate Student Portland State University

Date

I hereby permit

to participate as a subject in the study by Kathy McCausland.

Signed 
APPENDIX B

RESPONSE FORM

UNRELATED WORDS

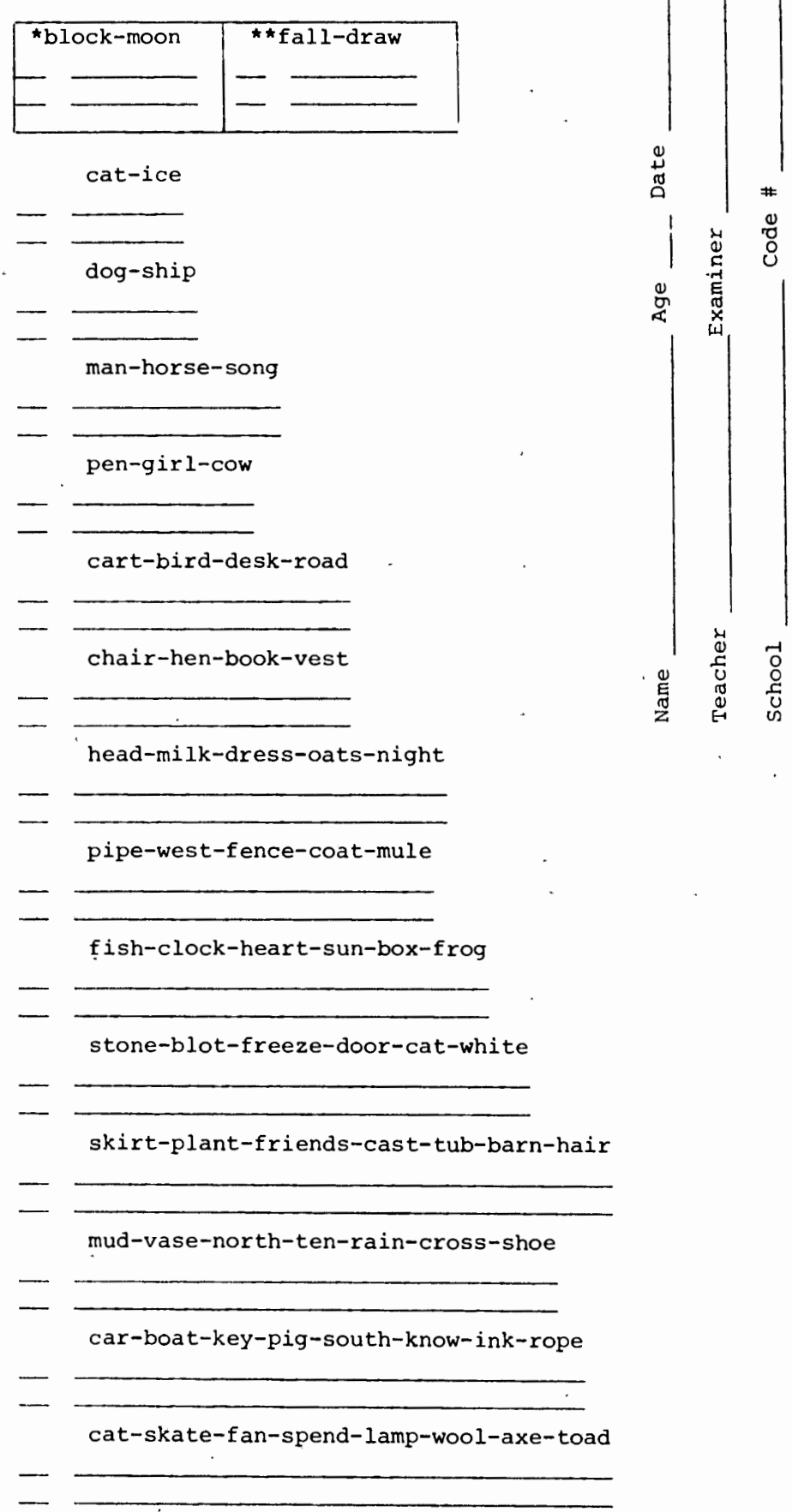




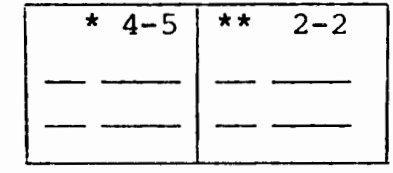

9-1

$-\overline{2-9}$

- -

$8-1-1$

$-\overline{6-4-9}$

$-\frac{-}{2-8-3-3}$

$$
-\frac{}{6-3-5-1}
$$$$
-\overline{-}
$$$$
=\overline{6-1-4-2-8}
$$

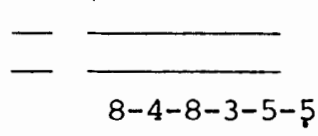

$$
-\frac{}{2-9-6-1-8-3}
$$$$
=\frac{}{3-6-1-9-2-3-9}
$$$$
=\overline{5-3-6-9-8-8-2}
$$

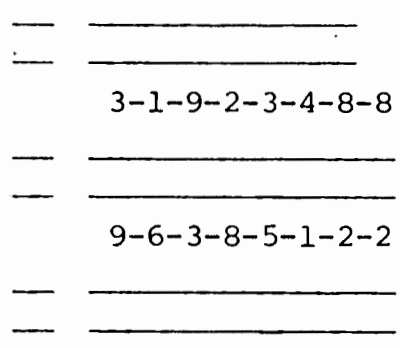

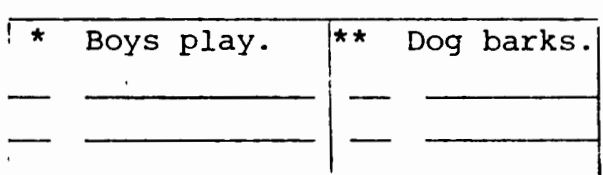

Tom left.

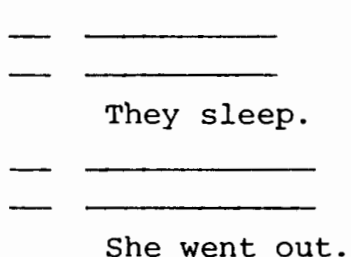

She went out.
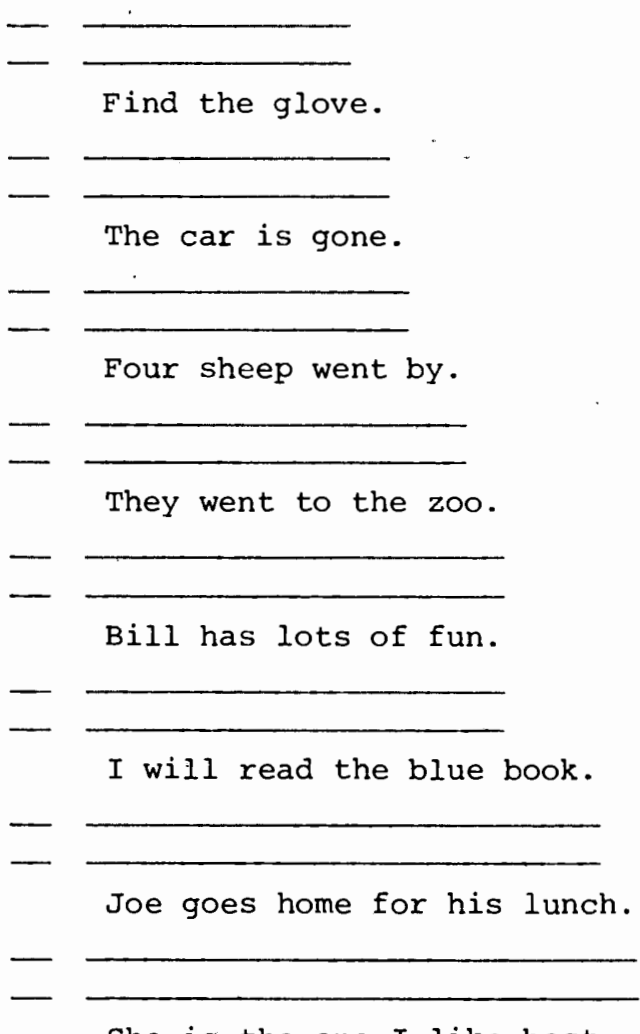

She is the one I like best.
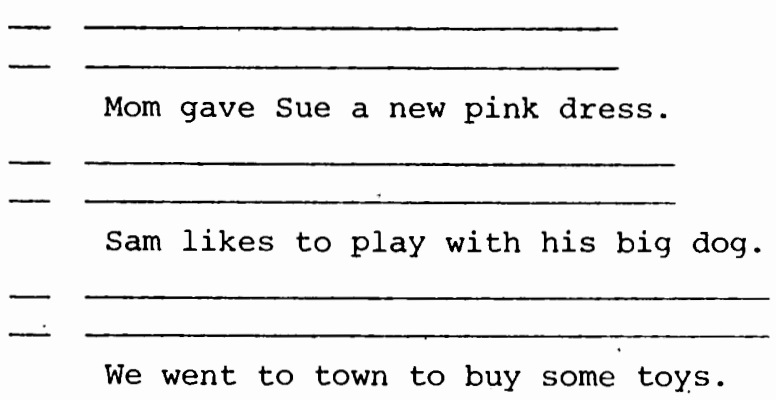

We went to town to buy some toys. 
NONSENSE WORDS

\begin{tabular}{|rr|rr|}
\hline$*$ /Seb-dza & $/$ & $* *$ & /gorset-1m/ \\
-1 & 1 & 1 & 1 \\
-1 & 1 & -1 & $/$ \\
\hline
\end{tabular}

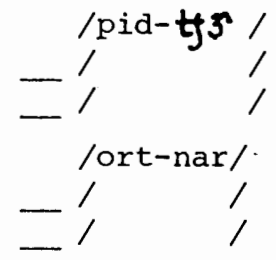

/pem-krIg-brIn/

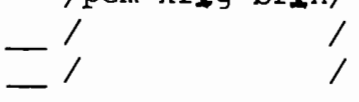

/taf-mv $\int-s u m /$

$-1,1$

/tuf-1ndz-wep-dit/

$\begin{array}{ll}1 & 1 \\ -1 & 1\end{array}$

/ t 3 -ral-Sar-han/

$\begin{array}{ll}1 & 1 \\ -1 & 1\end{array}$

. $/ \gamma g-1<f-b o g-2 a b-r a z /$

$\begin{array}{ll}1 & 1 \\ -1 & 1\end{array}$

/fodz-hEv-nIf-ak-fuz/

$\begin{array}{ll}1 & 1 \\ -1 & 1\end{array}$

/ Int-mat-atrop-grub-png-rg/

- 11

/lan-ta-nip-1In-dzsd-ka/

-1 1

/zar-sad-wem-fIf-twan-bro-drat/

-1

/vo-do $\int-I s-z I k-a I n-j o b-z u p /$

-1

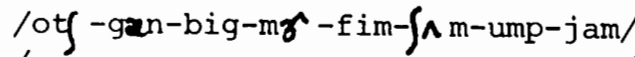

1
-1

/troen-zab-nzyk-bem-wamp-mif-t\&g-bup/

$\begin{array}{ll}1 & 1 \\ -1 & 1\end{array}$ 
RELATED WORDS

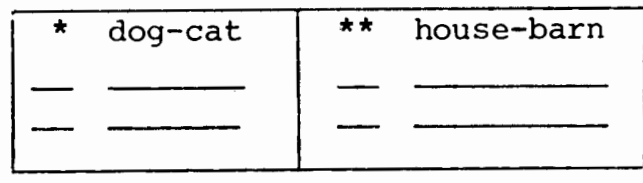

car-bus

- -

$\mp \frac{}{\text { cow-goat-horse }}$

- $-\frac{}{\text { see-hear-smell }} \overline{\text { chair-lamp-couch-rug }}$

- $\frac{.}{\text { train-ship-plane-boat-truck }}$

rain-hail-ice-snow-sleet

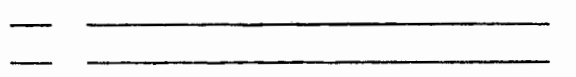

talk-yell-scream-cry-shout-sigh

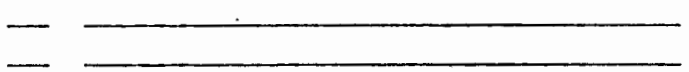

socks-tie-be1t-coat-shirt-pants

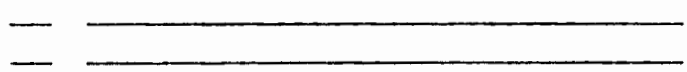

bowl-plate-spoon-cup-fork-glass-knife

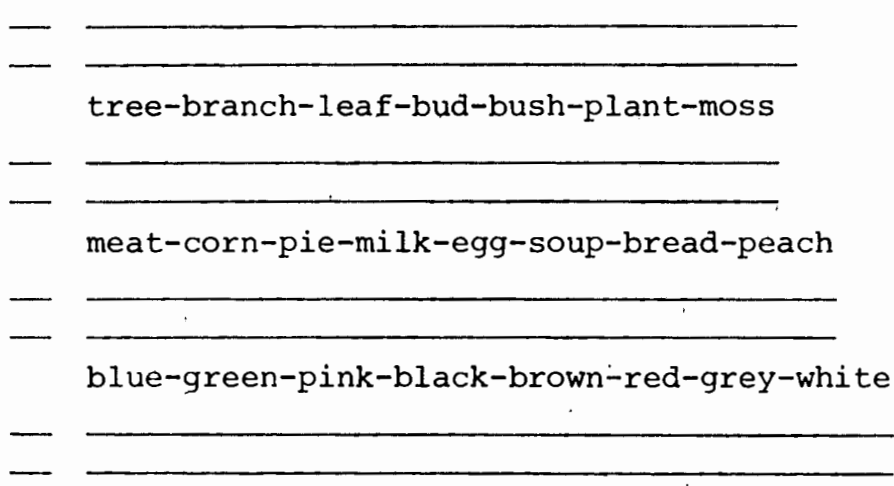


APPENDIX C

TEST RANDOMIZING LIST

(SUBJECT TEST ORDER)

1. 54213

16. 41523

2. 42531

17. 32145

3. 34125

18. 35124

4. 43251

19. 51423

5. 21435

20. 12345

6. 51243

21. 45132

7. 41253

22. 21453

8. 34251

23. 42351

9. 42351

24. 31245

10. 43512

25. 13452

11. 43215

26. 54312

12. 14253

27. 41532

13. 25341

28. 51324

14. 41235

29. 24153

15. 13524

30. 32145 
APPENDIX C

TEST RANDOMIZING LIST

(SUBJECT TEST ORDER)

1. 54213

2. 42531

3. 34125

4. 43251

5. 21435

6. 51243

7. 41253

8. 34251

9. 42351

10. 43512

11. 43215

12. 14253

13. 25341

14. 41235

15. 13524
16. 41523

17. 32145

18. 35124

19. 51423

20. 12345

21. 45132

22. 21453

23. 42351

24. 31245

25. 13452

26. 54312

27. 41532

28. 51324

29. 24153

30. 32145 